Article

\title{
Luminescent Studies on Germanate Glasses Doped with Europium Ions for Photonic Applications
}

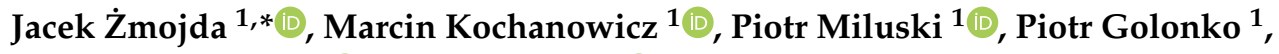

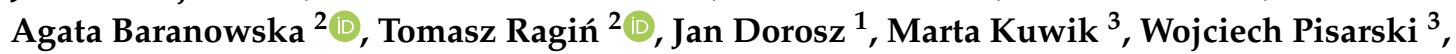 \\ Joanna Pisarska ${ }^{3}$, Renata Szal ${ }^{4}$, Gabriela Mach ${ }^{4}$, Bartosz Starzyk ${ }^{4}$, Magdalena Leśniak ${ }^{4}$ (D), \\ Maciej Sitarz ${ }^{4}$ and Dominik Dorosz ${ }^{4}$ (D)
}

1 Faculty of Electrical Engineering, Bialystok University of Technology, 45D Wiejska Street, 15-351 Bialystok, Poland; m.kochanowicz@pb.edu.pl (M.K.); p.miluski@pb.edu.pl (P.M.); piotr@neoweb.pl (P.G.); doroszjan@pb.edu.pl (J.D.)

2 Faculty of Mechanical Engineering, Bialystok University of Technology, 45C Wiejska Street, 15-351 Bialystok, Poland; a.baranowska@pb.edu.pl (A.B.); t.ragin@pb.edu.pl (T.R.)

3 Institute of Chemistry, University of Silesia, 9 Szkolna Street, 40-007 Katowice, Poland; marta.kuwik88@gmail.com (M.K.); wojciech.pisarski@us.edu.pl (W.P.); joanna.pisarska@us.edu.pl (J.P.)

4 Faculty of Materials Science and Ceramics, AGH University of Science and Technology, 30 Mickiewicza Av., 30-059 Krakow, Poland; renata.szal@agh.edu.pl (R.S.); machgabriela1@gmail.com (G.M.); bar.s@wp.pl (B.S.); mlesniak@agh.edu.pl (M.L.); msitarz@agh.edu.pl (M.S.); ddorosz@agh.edu.pl (D.D.)

* Correspondence: j.zmojda@pb.edu.pl; Tel.: +48-692-995-305

Received: 15 May 2020; Accepted: 16 June 2020; Published: 23 June 2020

check for updates

\begin{abstract}
Glass and ceramic materials doped with rare earth (RE) ions have gained wide interest in photonics as active materials for lasers, optical amplifiers, and luminescent sensors. The emission properties of RE-doped glasses depend on their chemical composition, but they can also be tailored by modifying the surrounding active ions. Typically, this is achieved through heat treatment (including continuous-wave and pulsed lasers) after establishing the ordering mechanisms in the particular glass-RE system. Within the known systems, silicate glasses predominate, while much less work relates to materials with lower energy phonons, which allow more efficient radiation sources to be constructed for photonic applications. In the present work, the luminescent and structural properties of germanate glasses modified with phosphate oxide doped with $\mathrm{Eu}^{3+}$ ions were investigated. Europium dopant was used as a "spectroscopic probe" in order to analyze the luminescence spectra, which characterizes the changes in the local site symmetries of $\mathrm{Eu}^{3+}$ ions. Based on the spectroscopic results, a strong influence of $\mathrm{P}_{2} \mathrm{O}_{5}$ content was observed on the excitation and luminescence spectra. The luminescence study of the most intense ${ }^{5} \mathrm{D}_{0} \rightarrow{ }^{7} \mathrm{~F}_{2}$ (electric dipole) transition revealed that the increase in the $\mathrm{P}_{2} \mathrm{O}_{5}$ content leads to the linewidth reduction (from $15 \mathrm{~nm}$ to $10 \mathrm{~nm}$ ) and the blue shift $(\sim 2 \mathrm{~nm})$ of the emission peak. According to the crystal field theory, the introduction of $\mathrm{P}_{2} \mathrm{O}_{5}$ into the glass structure changes the splitting number of sublevels of the ${ }^{5} \mathrm{D}_{0} \rightarrow{ }^{7} \mathrm{~F}_{1}$ (magnetic dipole) transition, confirming the higher polymerization of fabricated glass. The slightly different local environment of $\mathrm{Eu}^{3+}$ centers the results in a number of sites and causes inhomogeneous broadening of spectral lines. It was found that the local asymmetry ratio estimated by the relation of $\left({ }^{5} \mathrm{D}_{0} \rightarrow{ }^{7} \mathrm{~F}_{2}\right) /\left({ }^{5} \mathrm{D}_{0} \rightarrow{ }^{7} \mathrm{~F}_{1}\right)$ transitions also confirms greater changes in local symmetry around $\mathrm{Eu}^{3+}$ ions. Our results indicate that modification of germanate glass by $\mathrm{P}_{2} \mathrm{O}_{5}$ allows control of their structural properties in order to functionalize the emissions for application as luminescent light sources and sensors.
\end{abstract}

Keywords: germanate glass; europium oxide; luminescent properties; spectroscopic probe 


\section{Introduction}

Many photonic applications are based on active waveguide systems. Currently, active hybrid structures are proposed, in which crystalline phases are introduced within the amorphous matrix using various methods, including thermal treatment [1], direct doping [2], chemical vapor deposition (CVD) [3], and 3D printing [4]. All of these methods require glasses with modified structural properties, ensuring the conditions for obtaining new luminescent properties (from embedded active structures) while maintaining the stability of the hybrid system [5-7].

This opens a new direction to develop special glasses and optical fibers with unique structural lattice geometries. enabling effective light control. Recently, many novel photonic materials have combined two glass-forming elements with relatively different phonon energies: antimony-borate [8,9], lead-germanate [10,11], lead-phosphate [12,13], germanate-bismuth [14,15], or antimony-phosphate [16,17]. It is evident that this approach allows transparent and thermally stable glass to be achieved, which is useful in optical fiber fabrication. Additionally, due to the low phonon energy, higher efficiency of radiative transitions in lanthanide ions is achieved. Among various glass-forming oxides, the germanate glasses have been extensively investigated due to their unique material and optical properties, such as their low phonon energy (approximately $800 \mathrm{~cm}^{-1}$ ), good thermal stability, wide transparency window (from $0.35 \mu \mathrm{m}$ to $5 \mu \mathrm{m}$ ), and good lanthanide ion solubility [18-20]. In the 1990 s, one of the popular glass systems- $\mathrm{GeO}_{2}-\mathrm{Ga}_{2} \mathrm{O}_{3}-\mathrm{BaO}$ (GGB)-was developed as a candidate for optical fibers doped with rare earth ions [21]. Until now, these glasses have been modified by various oxides [22] and fluorides [23], however novel luminescent properties can be proposed. In our earlier works, we showed that the substitution of $\mathrm{BaO}$ by $\mathrm{Sb}_{2} \mathrm{O}_{3}$ and $\mathrm{TeO}_{2}$ in $\mathrm{GGB}$ glasses doped with $\mathrm{Eu}^{3+}$ ions led to the polymerization of the structure and ordering processes, along with increasing amounts of modifiers [24,25]. The choice of europium as a well-known "structural probe" allowed investigation of the crystal field symmetry in photonic materials [26]. Additionally, $\mathrm{Eu}^{3+}$ is one of the most important lanthanide ions, characterized by strong visible emissions, making it applicable in lighting, biochemical and biomedical sensing, as well as spectral imaging [27-29]. The other reasons for the popularity of europium ions in the field of photonics are their relevant emission properties resulting from $4 f \rightarrow 4 f$ transitions, whose positions are practically independent of ligands [30]. Therefore, the $\mathrm{Eu}^{3+}$ ions play an important role in the luminescence field, and their strong and narrow orange-red emission have been widely used in phosphors and display devices [31-33]. Moreover, due to its relatively simple energy level structure, the efficient excitation of europium is achieved by radiation from the UV spectral range (300-400 nm). Thus, incorporation of europium to different optical materials provides an opportunity to use it as UV-sensitive marker in fingerprint technique, fluorescence diagnosis or biomarkers [34-36].

In our current research, we focused on the role of $\mathrm{P}_{2} \mathrm{O}_{5}$ in luminescent and structural properties of GGB glasses doped with $\mathrm{Eu}^{3+}$ ions. The phosphorous oxide is characterized by high phonon energy $\left(1200 \mathrm{~cm}^{-1}\right)$ and reduces clustering effects via non-bridging oxygen formation, better incorporating rare earth ions promoting more efficient emissions than pure germanate glasses [37]. Even more interesting is that the $\mathrm{P}_{2} \mathrm{O}_{5}$ can be used as a nucleating agent for transparent glass-ceramic materials [38,39]. In view of the above, it is important to find a suitable composition of germanate glass that might be potentially used to produce the glass-ceramic material with functionalized luminescent properties. Taking into account the possible application of the investigated glass in light-emitting devices, the chemical composition of glass was modified by gradually replacing the $\mathrm{BaO}$ by $\mathrm{P}_{2} \mathrm{O}_{5}$ and by fixing the $\mathrm{Eu}^{3+}$ doping level $(0.2 \mathrm{~mol}$ \%). Deconvolution of mid-infrared (MIR) absorbance spectra was applied to analyze the strong impacts of $\mathrm{P}^{-} \mathrm{O}^{-}$bond vibration and non-bridging oxygen (NBO) on the maximization of the phonon energy of the glass matrix. Luminescence spectra and emission kinetics in the visible range were investigated in two channels of excitation at the $394\left({ }^{7} \mathrm{~F}_{0} \rightarrow{ }^{5} \mathrm{~L}_{6}\right)$ and $464 \mathrm{~nm}\left({ }^{7} \mathrm{~F}_{0} \rightarrow{ }^{5} \mathrm{D}_{2}\right)$ wavelengths. To the possible relation between the local structure of the fabricated germanate glass with the luminescent properties of $\mathrm{Eu}^{3+}$ ions, the effect of phosphorous oxide on the profiles of luminescence spectra was analyzed in detail. 


\section{Material and Methods}

Glasses with molar composition of $50 \mathrm{GeO}_{2}-10 \mathrm{Ga}_{2} \mathrm{O}_{3}-(40-\mathrm{x}) \mathrm{BaO}-\mathrm{xP}_{2} \mathrm{O}_{5}-0.2 \mathrm{Eu}_{2} \mathrm{O}_{3}$ (labelled as GGBxPEu), where $\mathrm{x}=0,10,20,30,40 \mathrm{~mol} . \%$, were melted in an alumina crucible at $1550{ }^{\circ} \mathrm{C}$ for $2 \mathrm{~h}$. The glass melt was poured into a brass plate at room temperature (RT) and then annealed at close to transformation temperature $\mathrm{T}_{\mathrm{g}}$ for $12 \mathrm{~h}$ to release the internal stress from the quench. Next, glasses were cooled down to room temperature and polished to meet the requirements for optical measurements.

X-ray diffraction studies were carried out on the X'Pert Pro X-ray diffractometer supplied by PANalytical (Eindhoven, Netherlands) with $\mathrm{Cu} \mathrm{K}_{\alpha 1}$ radiation $(\lambda=1.54056 \AA)$ in the $2 \theta$ range of $5^{\circ}-90^{\circ}$. The step size, time per step, and scan speed were $0.017^{\circ}, 184.79 \mathrm{~s}$, and $0.011^{\circ} / \mathrm{s}$, respectively. The X-ray tube was operated at $40 \mathrm{kV}$ and $40 \mathrm{~mA}$ and a scintillation detector was used to measure the intensity of the scattered X-rays. In the Supplementary Materials, the schematic of the XRD setup is described in detail. The morphologies of prepared samples were examined using an FEI Company Nova Nano SEM 200 scanning electron microscope (Hillsboro, OR, USA). The MIR spectra of the samples were obtained with a Fourier spectrometer (Bruker Optics-Vertex70V, Rheinstetten, Germany). The measurements were performed using the $\mathrm{KBr}$ pellet technique. Absorption spectra were recorded at 128 scans and a resolution of $4 \mathrm{~cm}^{-1}$. The MIR spectra were deconvoluted into component bands using the Opus-7.2 program.

The excitation and luminescence spectra of the glasses in the range of 350-750 $\mathrm{nm}$ were measured using the Jobin Yvon Fluoromax 4 spectrophotometer (HORIBA, Piscataway, NJ, USA). A PTI QuantaMaster QM40 system (Photon Technology International, Birmingham, NJ, USA) coupled with a tunable pulsed optical parametric oscillator (OPO) pumped by the third harmonic of the Nd:YAG laser (OpotekOpolette 355 LD, OPOTEK,Carlsband, CA, USA) was used for luminescence decay measurements. The laser system was equipped with a double $200 \mathrm{~mm}$ monochromator, a multimode UV-VIS PMT (R928), and Hamamatsu H10330B-75 detectors controlled by a computer. Luminescence decay curves were recorded and stored by a PTI ASOC-10 (USB-2500) oscilloscope with an accuracy of $\pm 1 \mu \mathrm{s}$.

\section{Results and Discussion}

\subsection{Structural Studies}

The X-ray diffraction method was used to determine the character of the obtained samples. Figure 1 shows the diffractograms of all synthesized samples. It is shown that all diffractograms include an amorphous halo effect ranging between $20^{\circ}$ and $30^{\circ} 2 \theta$, indicating their amorphous character. However, the diffractogram of the GGB20PEu sample (Figure 2), in addition to the amorphous halo, presents reflexes derived from the crystalline phase. The visible reflexes originate from the hexagonal phase of $\mathrm{GaPO}_{4}[40,41]$. The reflexes indicate glass structure ordering along with the addition of $\mathrm{P}_{2} \mathrm{O}_{5}$ and decrease of $\mathrm{BaO}$ until the $20 \mathrm{~mol} \%$ content is reached, and the possible creation of glass-ceramic material. Further replacing $\mathrm{BaO}$ with $\mathrm{P}_{2} \mathrm{O}_{5}$ causes disordering of the glass network, which is confirmed by the disappearance of reflexes.

Nonetheless, the observed crystalline phase was not detected under the scanning electron microscope as its crystals were probably too small (Figure 3). Additionally, SEM pictures include artifacts, which are crumbs created during the sample preparation process. The visible bulks are not part of the sample structure, but are unavoidable artifacts created while preparing the sample for testing. 


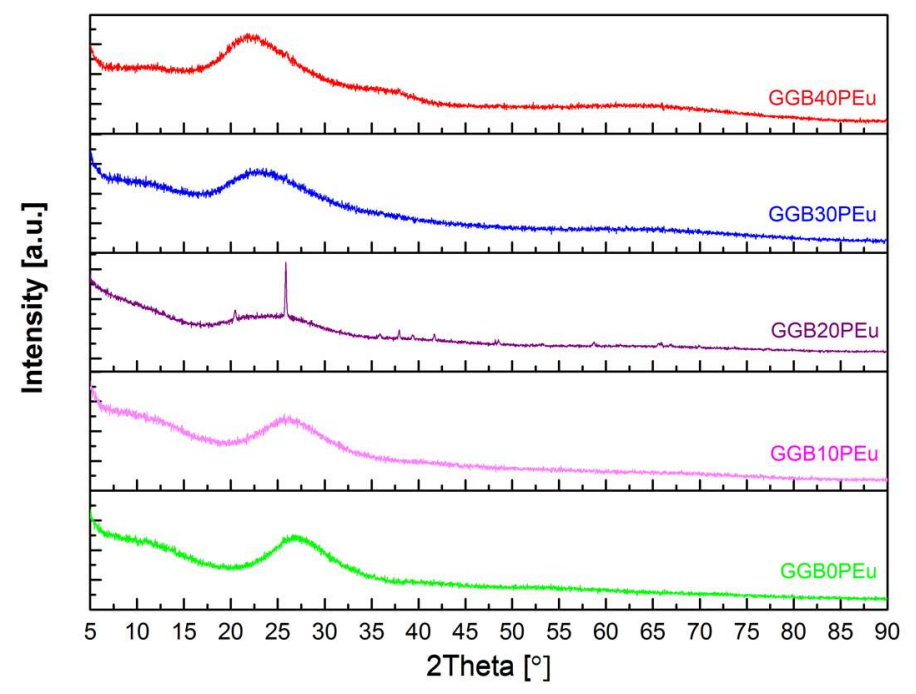

Figure 1. Diffractograms of the GGBxP_Eu glasses.

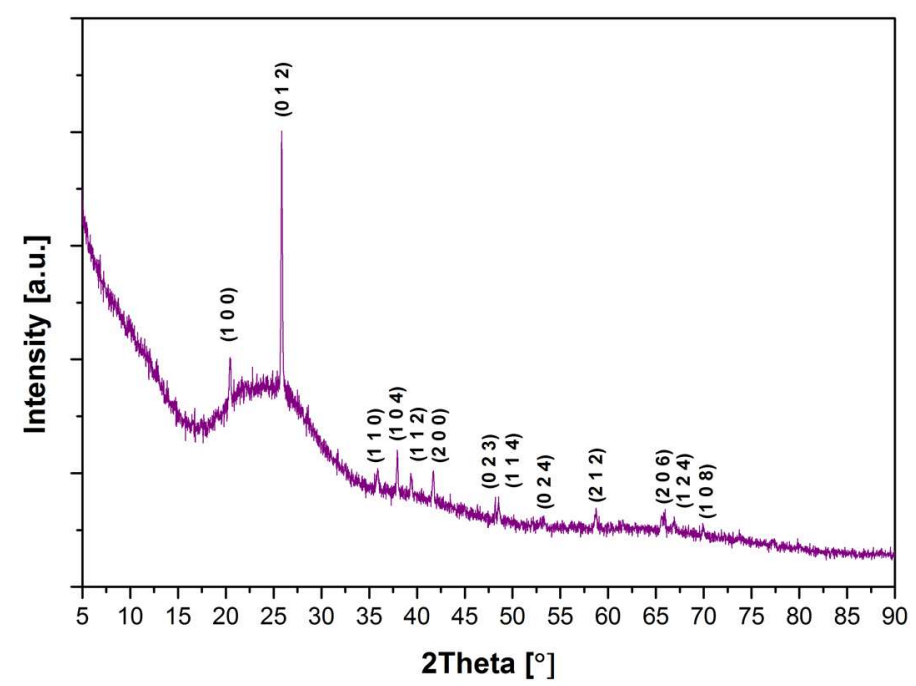

Figure 2. XRD pattern of the GGB20PEu glass sample with hkl crystalline planes for $\mathrm{GaPO}_{4}$.
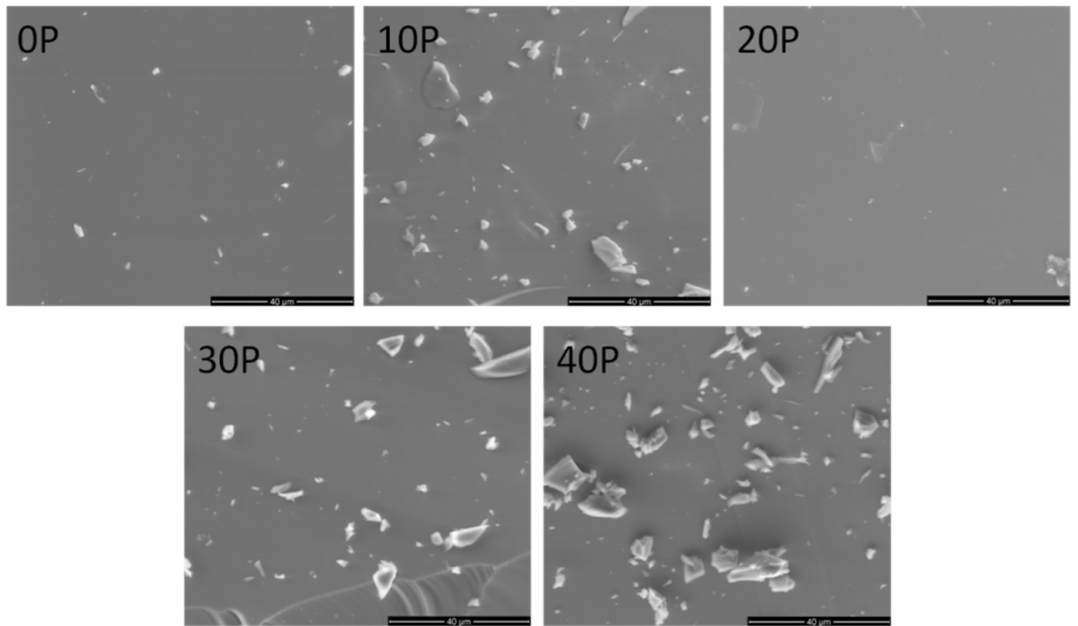

Figure 3. Scanning electron microscope images of samples from the GGBxP_Eu system (xP determines the $\mathrm{O}_{5}$ in the sample) 
The influence of $\mathrm{P}_{2} \mathrm{O}_{5}$ on the glass structure was analyzed on the basis of deconvoluted MIR spectra of $50 \mathrm{GeO}_{2}-10 \mathrm{Ga}_{2} \mathrm{O}_{3}-(40-\mathrm{x}) \mathrm{BaO}-\mathrm{xP}_{2} \mathrm{O}_{5}$ samples performed in the $400-1700 \mathrm{~cm}^{-1}$ range. The MIR spectrum of the glass sample free of phosphorus oxide is presented in Figure 4. The bands between 700 and $1000 \mathrm{~cm}^{-1}$ belong to asymmetric stretching vibrations of Ge-O-Ge bonds and symmetric stretching of broken $\mathrm{Ge}-\mathrm{O}^{-}$bonds. Bonds between 400 and $700 \mathrm{~cm}^{-1}$ can be ascribed to bending vibration of Ge-O-Ge bonds [42]. The MIR spectra of samples free of phosphorus oxide and enriched in $40 \mathrm{~mol} \%$ barium oxide show two bands at around 790 and $722 \mathrm{~cm}^{-1}$, which are ascribed broken bonds of Ge-O ${ }^{-}(\mathrm{NBOs})$ and bonds in $\left[\mathrm{GeO}_{6}\right]$ units, respectively. A less intensive band at around $925 \mathrm{~cm}^{-1}$ is associated with asymmetric stretching and Ge-O-Ge bond vibration. The high intensity of the bands corresponding to non-bridging oxygen atom (NBO) vibration resulting in bonds breaking inside the glass network is caused by the high content of barium oxide, which is a glass modifier [43-46].

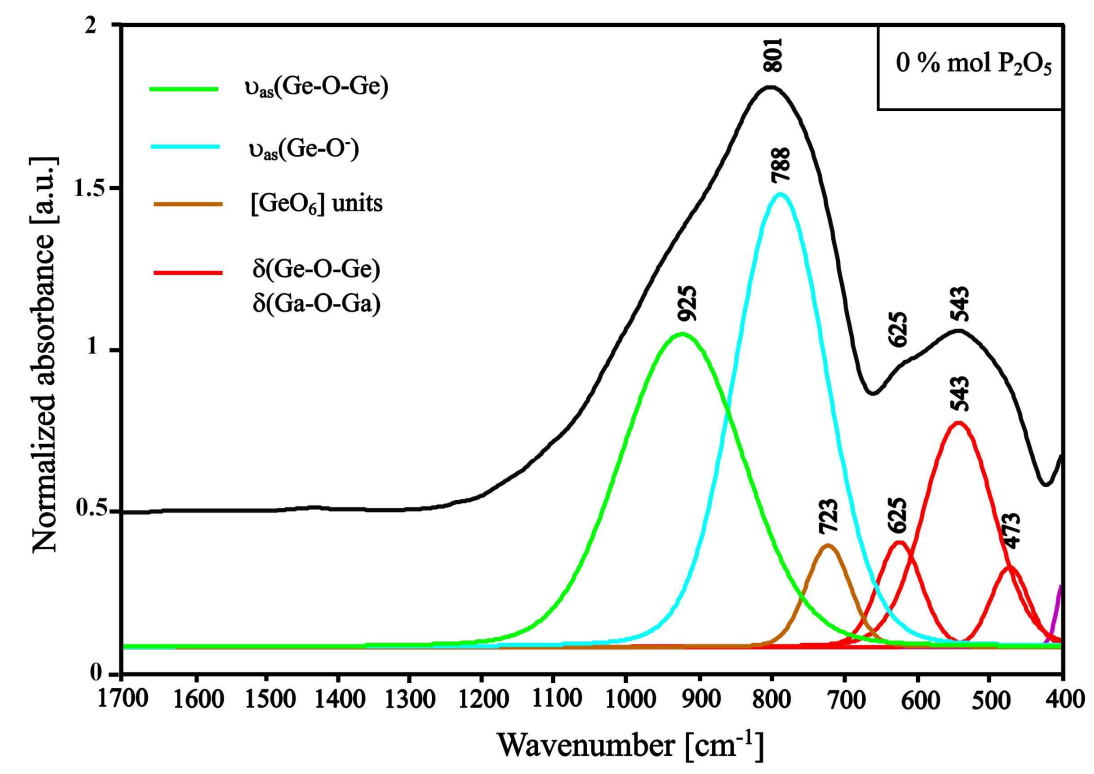

Figure 4. Deconvoluted spectrum of GGB0PEu glass sample (without $\mathrm{P}_{2} \mathrm{O}_{5}$ ).

The replacement of barium oxide in the amount of $20 \mathrm{~mol} \%$ by phosphorus oxide causes the appearance of new bands $\left(1000-1350 \mathrm{~cm}^{-1}\right.$ region) related to the bonds in $\left[\mathrm{PO}_{4}\right]$ units and broken $\mathrm{P}_{-}-\mathrm{O}^{-}$ bonds (Figure 5) $[47,48]$. Additionally, bands at $764 \mathrm{~cm}^{-1}$, which derive from $\mathrm{Ge}-\mathrm{O}^{-}$bond vibrations and bond vibrations in $\left[\mathrm{GeO}_{6}\right]$ units, are characterized by smaller intensities than the parallel bands from the spectrum in Figure 5. They are caused by the reduction of the content of the glass structure modifier (BaO). Moreover, the band at $1052 \mathrm{~cm}^{-1}$ in the spectrum in Figure 5 can be ascribed to NBO vibrations in $\mathrm{PO}_{3}$ mode in the $\mathrm{Q}_{1}$ tetrahedra unit [49]. These phenomena can be explained by the presence of the high content of barium oxide inside the glass structure and the presence of $\mathrm{Ga}_{2} \mathrm{O}_{3}$ in the glass set, which can be treated as a glass modifier. Additionally, the spectrum in Figure 5 presents sharper bandwidths with a lower value for the full width at half-maximum (FWHM) compared with the other spectra, which could indicate the occurrence of areas of long-range ordering inside the glass structure-the beginning of the crystallization processes.

When the amount of phosphorus oxide exceeds $20 \mathrm{~mol} \%$, the band at around $774 \mathrm{~cm}^{-1}$ ascribed to $\mathrm{Ge}-\mathrm{O}^{-}$bond vibrations and bond vibrations in the $\left[\mathrm{GeO}_{6}\right]$ units appears again, which could indicate depolymerization processes (Figure 6). Additionally, an increase in the intensity of the band derived from P-O- bond vibration $\left(\sim 1050 \mathrm{~cm}^{-1}\right)$ is noticeable (Figure 5). These aspects could be due to the activity of $\mathrm{Ga}_{2} \mathrm{O}_{3}$ as a glass modifier. In general, $\mathrm{Ga}_{2} \mathrm{O}_{3}$ in the glass set can be treated as a glass-forming element and modifier, which depends on its amount and the types of glass elements [50]. The increased molar content of $\mathrm{P}_{2} \mathrm{O}_{5}$ and the reduced content of $\mathrm{BaO}$ emphasize the role of $\mathrm{Ga}_{2} \mathrm{O}_{3}$ as a glass modifier, which consequently cause breakage of the bonds in the glass structure. The deconvolution of the 
spectrum of the sample containing 20 mol.\% of phosphorus oxide show the presence of P-O bond vibration in $Q_{1}$ and $Q_{2}$ units at $979 \mathrm{~cm}^{-1}$ and $1217 \mathrm{~cm}^{-1}$, and $1135 \mathrm{~cm}^{-1}$, respectively. The intensity of each band is on similar level, while further addition of phosphorus oxide and complete removal of barium oxide cause dominance of the band intensity derived from $Q_{2}$ units $\left(1178 \mathrm{~cm}^{-1}\right.$ and $\left.1301 \mathrm{~cm}^{-1}\right)$ over the band intensity derived from $\mathrm{Q}_{1}$ units $\left(956 \mathrm{~cm}^{-1}\right)$ (Figures 5 and 6$)$. The $\mathrm{P}_{2} \mathrm{O}_{5}$ addition and $\mathrm{BaO}$ removal increase the number of connections between $\left[\mathrm{PO}_{4}\right]$ units [47].

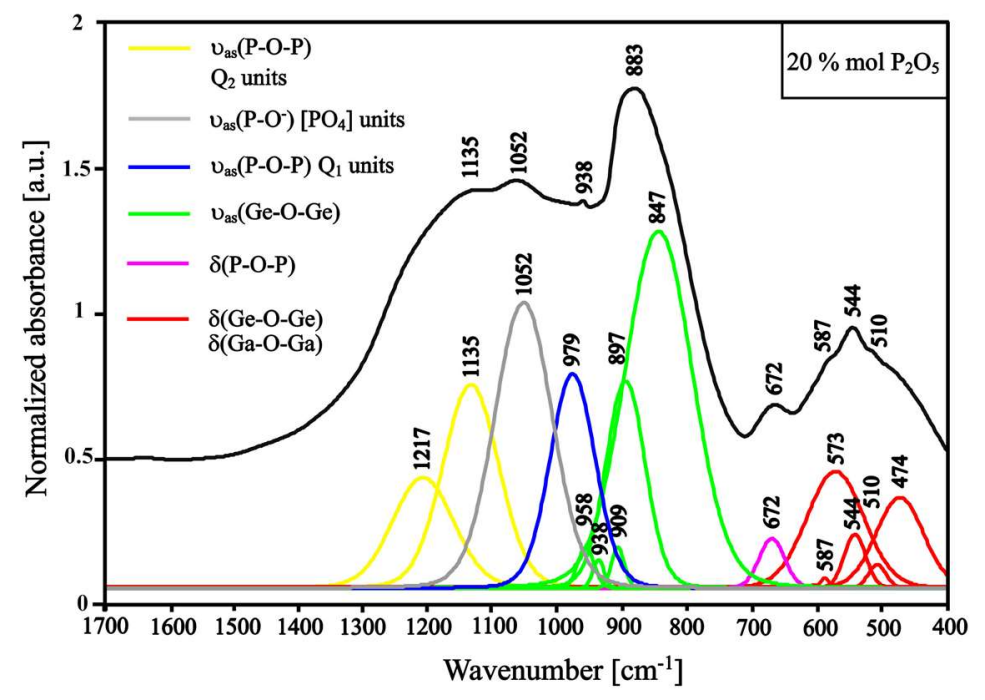

Figure 5. Deconvoluted spectrum of GGB20PEu glass sample (with 20 mol. $\%$ of $\mathrm{P}_{2} \mathrm{O}_{5}$ ).

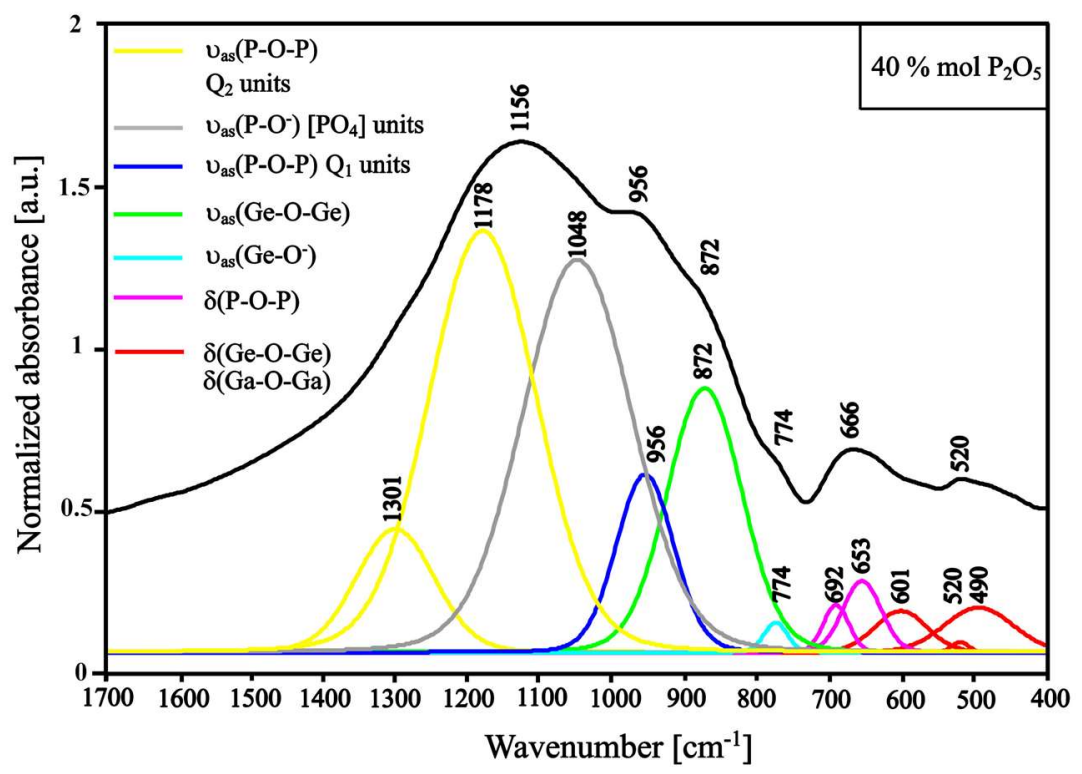

Figure 6. Deconvoluted spectrum of GGB40PEu glass sample (with 40 mol.\% of $\mathrm{P}_{2} \mathrm{O}_{5}$ ).

Along with the phosphorus oxide addition and the barium oxide removal, the ratio of the intensity of the bands ascribed to P-O and Ge-O bond vibration increases (Figures 4-6). The range between 400 and $700 \mathrm{~cm}^{-1}$ is the region where bands correspond to the bending of the bridging bond vibrations. Along with phosphorus oxide addition, the intensities of bands between 400 and $630 \mathrm{~cm}^{-1}$ decrease parallel with increasing intensities of bands between 630 and $700 \mathrm{~cm}^{-1}$, which can be ascribed to the bending vibrations of P-O-P bonds [47,49,51,52]. 


\subsection{Photoluminescence Excitation, Emission Spectra, and Luminescence Kinetics}

In order to investigate the effect of $\mathrm{P}_{2} \mathrm{O}_{5}$ content on optical properties of GGB glasses doped with europium ions, the excitation spectra monitored at $611 \mathrm{~nm}$ were analyzed (Figure 7). It is known that the observed five bands centered at the wavelengths of $362,382,393,415$, and $465 \mathrm{~nm}$ correspond to transitions from the ground state ${ }^{7} \mathrm{~F}_{0}$ to the higher energy states ${ }^{5} \mathrm{D}_{4},{ }^{5} \mathrm{~L}_{7},{ }^{5} \mathrm{~L}_{6},{ }^{5} \mathrm{D}_{3}$, and ${ }^{5} \mathrm{D}_{2}$, respectively. In the analyzed spectral range of 350-500 $\mathrm{nm}$, two bands are characterized as having the highest intensity. The band at $394 \mathrm{~nm}\left({ }^{7} \mathrm{~F}_{0} \rightarrow{ }^{5} \mathrm{~L}_{6}\right)$ is most commonly used for optical excitation of glasses doped with $\mathrm{Eu}^{3+}$ ions. A second one at $465 \mathrm{~nm}\left({ }^{7} \mathrm{~F}_{0} \rightarrow{ }^{5} \mathrm{D}_{2}\right)$, which is dominant in fabricated glasses, is called "hypersensitive transition" and strongly depends on the local environment of the europium ions [22]. In our experiment, the highest intensity of the ${ }^{7} \mathrm{~F}_{0} \rightarrow{ }^{5} \mathrm{D}_{2}$ transition was observed in glasses without $\mathrm{P}_{2} \mathrm{O}_{5}$ (GGBOPEu), while the introduction of phosphate oxides led to a slight decrease in excitation intensity up to $30 \mathrm{~mol} \%$ for $\mathrm{P}_{2} \mathrm{O}_{5}$. For glasses with maximal content of phosphorous (GGB40P) only, the intensity of the excitation band at $393 \mathrm{~nm}$ was on a similar level, but the "hypersensitive transition" intensity was still higher than ${ }^{7} \mathrm{~F}_{0} \rightarrow{ }^{5} \mathrm{~L}_{6}$ transitions.

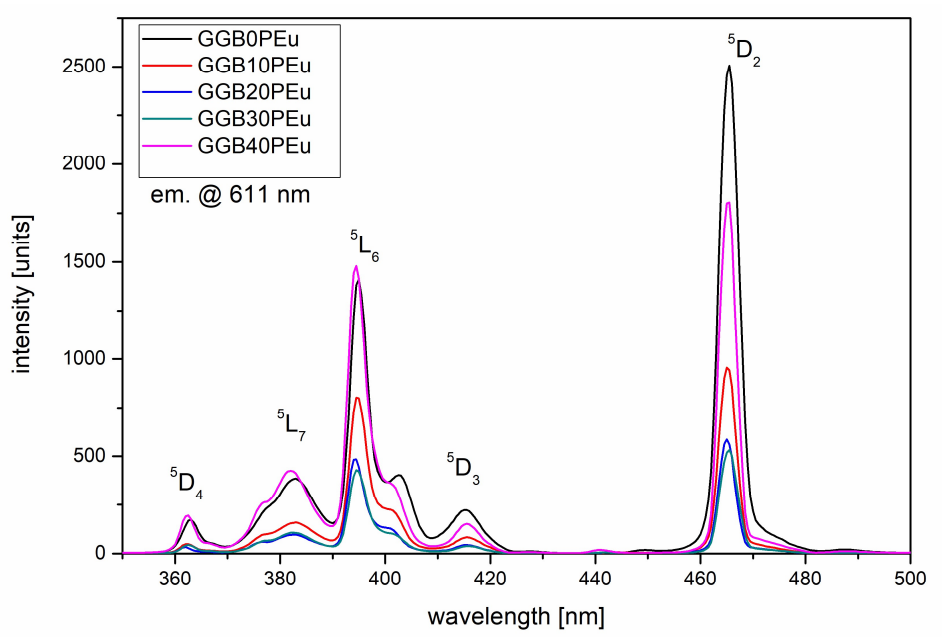

Figure 7. Excitation spectra (monitoring at $611 \mathrm{~nm}$ ) of $\mathrm{Eu}^{3+}$ ions doped GGBxPEu glass modified by $\mathrm{P}_{2} \mathrm{O}_{5}$.

Due to the different intensities of ${ }^{5} \mathrm{~L}_{6}$ and ${ }^{5} \mathrm{D}_{2}$ bands, the luminescence spectra in two excitation channels were analyzed. Figure $8 \mathrm{a}, \mathrm{b}$ presents the normalized luminescence spectra of GGB glasses modified by $\mathrm{P}_{2} \mathrm{O}_{5}$ and doped with $0.2 \mathrm{~mol} \%$ of $\mathrm{Eu}_{2} \mathrm{O}_{3}$ under 394 and $464 \mathrm{~nm}$ laser excitation, respectively. The normalization of all spectra to the ${ }^{5} \mathrm{D}_{0} \rightarrow{ }^{7} \mathrm{~F}_{1}$ transition, in which the intensity is independent of the host, provides a useful method for the fast determination of network changes in the vicinity of Eu ions. In both cases, the shape of the luminescence is similar and consists of five emission bands centered at the wavelengths of $575,589,611,650$, and $700 \mathrm{~nm}$, originating from ${ }^{5} \mathrm{D}_{0} \rightarrow{ }^{7} \mathrm{~F}_{\mathrm{J}}(\mathrm{J}=0,1 \ldots 4)$ transitions. Especially, two of the emission bands shown evident changes resulting from the $\mathrm{P}_{2} \mathrm{O}_{5}$ modification. The first is the ${ }^{5} \mathrm{D}_{0} \rightarrow{ }^{7} \mathrm{~F}_{1}$ transition, defined as the magnetic dipole (MD) transition, which is the most intensive transition in the spectra of materials with an inversion symmetry structure [53]. According to the selection rules, the intensity of the ${ }^{5} \mathrm{D}_{0} \rightarrow{ }^{7} \mathrm{~F}_{1}$ transition is independent of the ligands of Eu $\mathrm{u}^{3+}$ ions, hence the spectra normalization is helpful in the characterization of the site asymmetry of europium ions. Second, the ${ }^{5} \mathrm{D}_{0} \rightarrow{ }^{7} \mathrm{~F}_{2}$ transition belongs to the electric dipole (ED) transitions and is the dominant emission band in fabricated glasses. The intensity of this transition strongly depends on the local environment of $\mathrm{Eu}^{3+}$ ions and is usually called "hypersensitive transition". In our experiment, the intensity of the emission at $611 \mathrm{~nm}\left({ }^{5} \mathrm{D}_{0} \rightarrow{ }^{7} \mathrm{~F}_{2}\right)$ obtained for both excitation routes was changed as a function of the $\mathrm{P}_{2} \mathrm{O}_{5}$ concentration. Based on these changes, the asymmetric ratio (AR) intensities, defined as the relation of the electric dipole transition $\left({ }^{5} \mathrm{D}_{0} \rightarrow{ }^{7} \mathrm{~F}_{2}\right)$ to the magnetic dipole transition 
$\left({ }^{5} \mathrm{D}_{0} \rightarrow{ }^{7} \mathrm{~F}_{1}\right)$, were estimated (inset in Figure 8). The value of the $\left({ }^{5} \mathrm{D}_{0} \rightarrow{ }^{7} \mathrm{~F}_{2}\right) /\left({ }^{5} \mathrm{D}_{0} \rightarrow{ }^{7} \mathrm{~F}_{1}\right)$ transition ratio gives a factor of the degree of structural distortion from the inversion symmetry of the local environment of the europium ions [39]. We observed that replacing the $\mathrm{BaO}$ by $\mathrm{P}_{2} \mathrm{O}_{5}$ up to $20 \mathrm{~mol} . \%$ leads to a decrease of the asymmetric ratio, which is related to the partial structural arrangement in the ligand field around $\mathrm{Eu}^{3+}$ ions. This effect indicates that $\mathrm{Eu}^{3+}$ ions could be incorporated into the crystalline phase, which is in good agreement with our structural results (Figures 2 and 5). However, more interesting is the fact that the further increase of phosphate oxide has the opposite effect, whereby the asymmetric ratio increases. This phenomenon confirms that a higher concentration of $\mathrm{P}_{2} \mathrm{O}_{5}$ leads to "depolymerization" of a glassy network, resulting from an increase in the non-bridging oxygen (NBO) group [37]. In this way, the phosphorous oxide can change its role from being a glass modifier to a glass-forming compound.

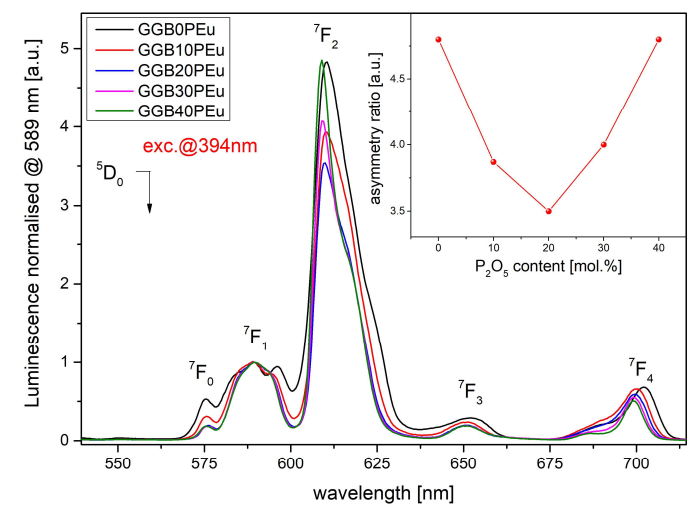

(a)

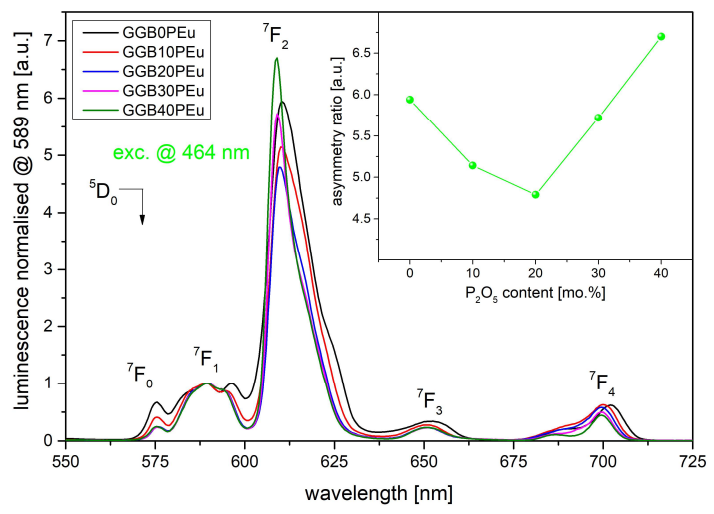

(b)

Figure 8. Luminescence spectra of $\mathrm{Eu}^{3+}$-ion-doped GGBxPEu glasses (a) under 394 and (b) under $465 \mathrm{~nm}$ of laser excitation. (Inset in both figures) Asymmetry ratio of Eu-doped GGBxPEu glass modified by $\mathrm{P}_{2} \mathrm{O}_{5}$.

The luminescence decay curves of GGBxPEu glasses doped with $\mathrm{Eu}^{3+}$ ions obtained under two excitation wavelengths $\left(\lambda_{\mathrm{exc}}=394\right.$ and $\left.464 \mathrm{~nm}\right)$ in a semi-logarithmic scale are presented in Figure 9. All obtained results are described by single-exponential approximation. The shortest lifetime of the ${ }^{5} \mathrm{D}_{0}$ state of $\mathrm{Eu}^{3+}$ was obtained for the glass without phosphorous oxide, which was similar to the other germanate-based glasses from the literature [11,23]. It is worth noting that the partial replacement of $\mathrm{BaO}$ by $\mathrm{P}_{2} \mathrm{O}_{5}$ in the glass network caused an almost two-fold increase in the luminescence lifetime of the ${ }^{5} \mathrm{D}_{0}$ state of $\mathrm{Eu}^{3+}$, increasing from $1.32 \mathrm{~ms}$ (GGBOPEu) to $2.19 \mathrm{~ms}$ (GGB20PEu). However, when the $\mathrm{BaO}$ was completely substituted by $\mathrm{P}_{2} \mathrm{O}_{5}$, the luminescence lifetime decreased slightly (Table 1 ). Additionally, the measured values of the luminescence lifetimes of the ${ }^{5} \mathrm{D}_{0}$ state for glasses with phosphorous oxide are comparable to the lifetimes in other phosphate glasses [27].

Due to the similar changing trends for the luminescence lifetime for both excitation wavelengths, we concluded that fabricated glasses are characterized by good homogeneity of $\mathrm{Eu}^{3+}$ centers (insets in Figure 9).

Further detailed analysis of the luminescence shape showed interesting effects in GGB glasses caused by partial replacement of $\mathrm{BaO}$ by $\mathrm{P}_{2} \mathrm{O}_{5}$ (Figure 10). Here, to compare the luminescence shape changes more easily, all spectra at the ${ }^{5} \mathrm{D}_{0} \rightarrow{ }^{7} \mathrm{~F}_{2}$ transition were normalized. To correlate structural changes with the luminescent properties of investigated glasses, we focused precisely on the changes of two transitions: (i) ${ }^{5} \mathrm{D}_{0} \rightarrow{ }^{7} \mathrm{~F}_{2}$, where the incorporation of $\mathrm{P}_{2} \mathrm{O}_{5}$ leads to a decrease of the spectral line bandwidth from $15 \mathrm{~nm}$ to $10 \mathrm{~nm}$ and a $2 \mathrm{~nm}$ shift of the emission peak towards shorter wavelengths; (ii) ${ }^{5} \mathrm{D}_{0} \rightarrow{ }^{7} \mathrm{~F}_{1}$, where the relation between the Stark sublevel presents a considerable number of slightly different sites for $\mathrm{Eu}^{3+}$ centers [54]. In the case of spectral broadening of the emission band at the wavelength of $611 \mathrm{~nm}\left({ }^{5} \mathrm{D}_{0} \rightarrow{ }^{7} \mathrm{~F}_{2}\right)$, the narrowing effect is connected with the higher heterogeneity 
of glassy structure in samples with a higher concentration of $\mathrm{P}_{2} \mathrm{O}_{5}[55,56]$. Additionally, the high phonon energy of $\mathrm{P}-\mathrm{O}$ bonds minimizes the energy migration between europium ions, hence the inhomogeneous broadening is lower. The blue-shift in the peak emission wavelength can be ascribed to the formation of non-bridging oxygen groups more than bridging oxygen groups in the GGBxP glass sample.

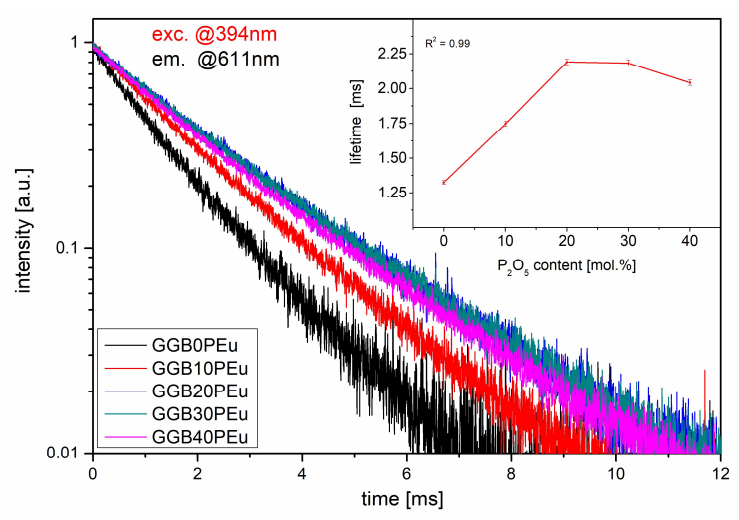

(a)

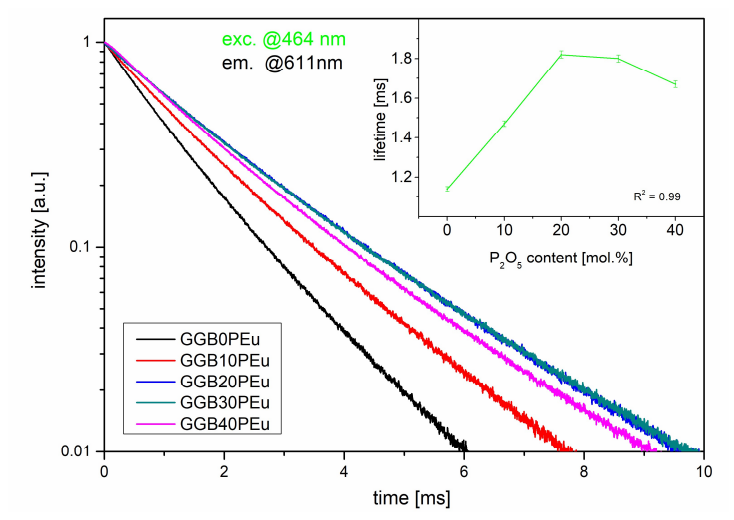

(b)

Figure 9. Luminescence decays of the ${ }^{5} \mathrm{D}_{0}$ energy level of europium ions in fabricated GGBxPEu glasses (a) under $394 \mathrm{~nm}$ laser excitation and (b) under $464 \mathrm{~nm}$ of laser excitation. (Inset) The changes in the lifetime as a function of $\mathrm{P}_{2} \mathrm{O}_{5}$ concentration.

Table 1. The ED/MD transition ratio and the $\tau_{394 \mathrm{~nm}}$ and $\tau_{464 \mathrm{~nm}}$ lifetime values of the ${ }^{5} \mathrm{D}_{0}$ level of $\mathrm{Eu}^{3+}$ ions.

\begin{tabular}{|c|c|c|c|c|}
\hline \multirow{2}{*}{ Glass Sample } & \multicolumn{2}{|c|}{ ED/MD Ratio } & \multirow{2}{*}{$\begin{array}{c}\tau_{394 \mathrm{~nm}} \\
{[\mathrm{~ms}] \pm 0.01 \mathrm{~ms}}\end{array}$} & \multirow{2}{*}{$\begin{array}{c}\tau_{464 \mathrm{~nm}} \\
{[\mathrm{~ms}] \pm 0.01 \mathrm{~ms}}\end{array}$} \\
\hline & exc. @394 nm & exc.@464 nm & & \\
\hline GGB10P & 4.8 & 5.9 & 1.32 & 1.14 \\
\hline GGB10P & 3.9 & 5.1 & 1.74 & 1.47 \\
\hline GGB20P & 3.5 & 4.8 & 2.19 & 1.82 \\
\hline GGB30P & 4 & 5.7 & 2.18 & 1.80 \\
\hline GGB40P & 4.8 & 6.7 & 2.04 & 1.67 \\
\hline
\end{tabular}

According to crystal field theory, the next analyzed ${ }^{5} \mathrm{D}_{0} \rightarrow{ }^{7} \mathrm{~F}_{1}$ transition directly shows the splitting of the ${ }^{7} \mathrm{~F}_{1}$ level. If the ${ }^{7} \mathrm{~F}_{1}$ level is not split then cubic or icosahedral crystal fields are observed. For hexagonal, tetragonal, and trigonal crystal fields, the ${ }^{7} \mathrm{~F}_{1}$ level is split for two components. In the case of the lowest symmetries (orthorhombic crystal fields), three sublevels occur in the ${ }^{7} \mathrm{~F}_{1}$ level $[53,57]$. The inset in Figure 10 shows a deconvoluted ${ }^{5} \mathrm{D}_{0} \rightarrow{ }^{7} \mathrm{~F}_{1}$ transition for GGB0P and GGB40P glasses. In our case, germanate glass without $\mathrm{P}_{2} \mathrm{O}_{5}$ is characterized by low symmetry and three Stark sublevels bands are easy to determine. Additionally, the intensities of all sub-bands are approximately the same. It is worth noting that replacing $\mathrm{BaO}$ with $40 \mathrm{~mol} \%$ of $\mathrm{P}_{2} \mathrm{O}_{5}$ leads to visible domination of the central emission sub-band. The obtained results confirm that europium ions in fabricated germanate glass can occupy two or three sites of symmetry, depending on the $\mathrm{P}_{2} \mathrm{O}_{5}$ concentration. 


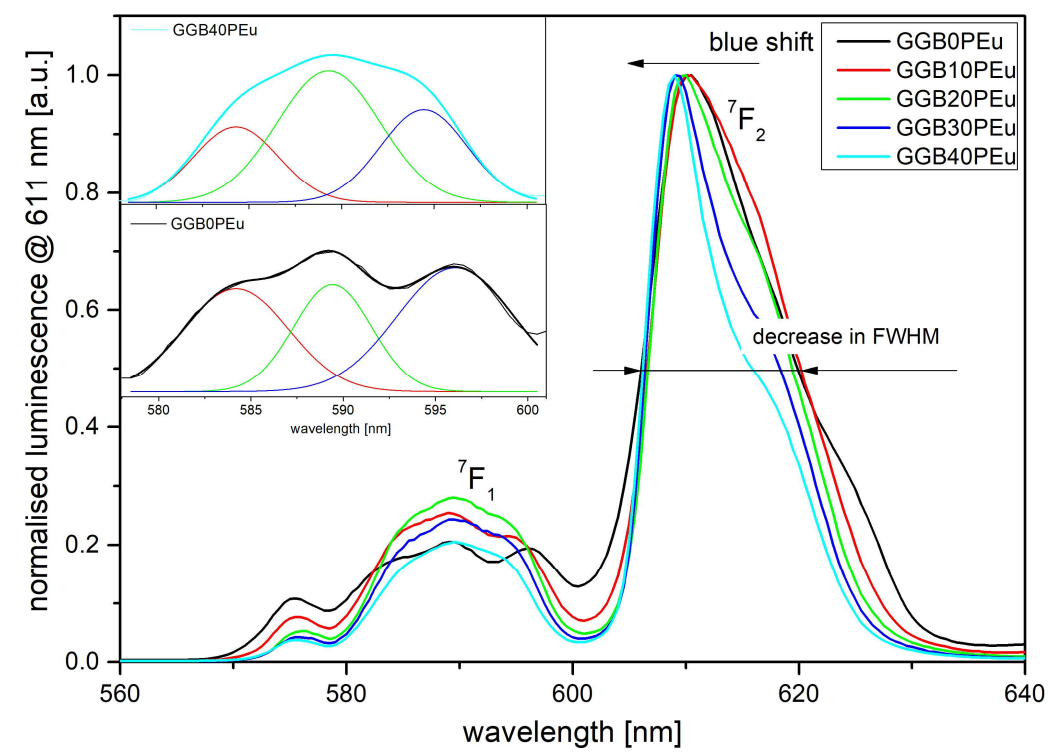

Figure 10. Normalized luminescence spectra of $\mathrm{Eu}^{3+}$-doped GGBxP glasses under $394 \mathrm{~nm}$ laser excitation. (Inset) Deconvolution of ${ }^{7} \mathrm{~F}_{1}$ multiplet for glasses with $40 \mathrm{~mol} \%$ of $\mathrm{P}_{2} \mathrm{O}_{5}$ (up) and without $\mathrm{P}_{2} \mathrm{O}_{5}$ (down). FWHM, full width at half-maximum.

\section{Conclusions}

The germanate glasses with $50 \mathrm{GeO}_{2}-10 \mathrm{Ga}_{2} \mathrm{O}_{3}-(40-\mathrm{x}) \mathrm{BaO}-\mathrm{xP}_{2} \mathrm{O}_{5}-0.2 \mathrm{Eu}_{2} \mathrm{O}_{3}$ molar compositions have been synthesized and investigated by XRD, SEM, MIR, and optical spectroscopy. MIR spectra analysis has shown that phosphorous oxide (up to 40 mol.\%) introduces additional bond vibration as ion co-forming in the network of a fabricated glass. The analysis of intensity changes of absorption bands confirmed that the reduction of barium oxide content was evident with a decrease in the intensity of bands related to Ge-O- vibrations and the disappearance of the band ascribed to P-Obond vibration. The luminescence studies carried out in two excitation routes for $\mathrm{Eu}^{3+}$ ions at $394 \mathrm{~nm}$ $\left({ }^{7} \mathrm{~F}_{0} \rightarrow{ }^{5} \mathrm{~L}_{6}\right)$ and $464 \mathrm{~nm}\left({ }^{7} \mathrm{~F}_{0} \rightarrow{ }^{5} \mathrm{D}_{2}\right)$ showed that replacing $\mathrm{BaO}$ with up to $20 \mathrm{~mol} \%$ of $\mathrm{P}_{2} \mathrm{O}_{5}$ leads to a decrease in the luminescence asymmetric ratio, which is in good agreement with structural results (XRD, MIR). In general, the values for asymmetric ratio suggest that in all samples the $\mathrm{Eu}^{3+}$ ions are located at sites without inversion symmetry. However, partial local long-range ordering was observed in GGB20PEu glass. Based on detailed analysis of the luminescence shapes of two main radiative transitions of $\mathrm{Eu}^{3+}$ ions, the spectral narrowing of the band at $611 \mathrm{~nm}\left({ }^{5} \mathrm{D}_{0} \rightarrow{ }^{7} \mathrm{~F}_{2}\right)$ and evident splitting of the emission band at $589 \mathrm{~nm}\left({ }^{5} \mathrm{D}_{0} \rightarrow{ }^{7} \mathrm{~F}_{1}\right)$ confirm that fabricated glasses are characterized by low symmetry (orthorhombic) of the local environment of europium ions. The obtained results indicate that chemical modification of germanate glass doped with europium ions by phosphorous oxide allows the design of functionalized luminescent properties, which are important for applications in modern light-emitting devices. In future work, we will extend our experiments towards glass-ceramic materials (especially in glass samples with visible nanocrystalization, such as GGB20PEu) and we will show the possibility of tuning the emissions from $\mathrm{Eu}^{3+}$ ions resulting from the nanostructurization of the local network, as well as the impact of the activator content.

Supplementary Materials: The following are available online at http://www.mdpi.com/1996-1944/13/12/2817/s1: Figure S1: Schematic diagram of the XRD setup.

Author Contributions: Conceptualization, D.D., J.D. and J.Ż.; methodology, R.S., J.Ż., M.S., J.P., W.P. and D.D.; validation, D.D, M.S., M.K. (Marcin Kochanowicz), P.M., and W.P.; formal analysis, A.B. and M.L.; investigation, R.S., A.B., T.R., M.K. (Marta Kuwik), and P.G.; resources, M.L., J.P., M.K. (Marcin Kochanowicz), and P.M.; writing—original draft preparation, R.S., M.L., G.M., B.S., T.R., P.G., M.K. (Marta Kuwik) and J.Ż.; writing—review and editing, A.B., M.L., D.D. and M.S.; visualization, J.Ż., G.M., B.S., and R.S.; supervision, J.D. and D.D.; project administration, D.D.; funding acquisition, D.D. All authors have read and agreed to the published version of the manuscript. 
Funding: This research was funded by the National Science Center of Poland, grant number 2016/23/B/ST8/00706. Conflicts of Interest: The authors declare no conflict of interest.

\section{References}

1. Gorni, G.; Velázquez, J.J.; Kochanowicz, M.; Dorosz, D.; Balda, R.; Fernández, J.; Durán, A.; Pascual, M.J. Tunable upconversion emission in NaLuF4-glass-ceramic fibers doped with $\mathrm{Er}^{3+}$ and $\mathrm{Yb}^{3+}$. RSC Adv. 2019, 9, 31699-31707. [CrossRef]

2. Szczodra, A.; Kuusela, L.; Norrbo, I.; Mardoukhi, A.; Hokka, M.; Lastusaari, M.; Petit, L. Successful preparation of fluorine containing glasses with persistent luminescence using the direct doping method. J. Alloys Compd. 2019, 787, 1260-1264. [CrossRef]

3. Mrázek, J.; Kašík, I.; Procházková, L.; Čuba, V.; Girman, V.; Puchý, V.; Blanc, W.; Peterka, P.; Aubrecht, J.; Cajzl, J.; et al. YAG Ceramic Nanocrystals Implementation into MCVD Technology of Active Optical Fibers. Appl. Sci. 2018, 8, 833. [CrossRef]

4. Hoon Yeub, J.; Eunsongyi, L.; Soo-Chan, A.; Yeonsoo, L.; Young Chul, J. 3D and 4D printing for optics and metaphotonics. Nanophotonics 2020. [CrossRef]

5. Escudero, A.; Becerro, A.I.; Carrillo-Carrión, C.; Núñez, N.O.; Zyuzin, M.V.; Laguna, M.; González-Mancebo, D.; Ocaña, M.; Parak, W.J. Rare earth based nanostructured materials: Synthesis, functionalization, properties and bioimaging and biosensing applications. Nanophotonics 2017, 6, 881. [CrossRef]

6. Wang, H.; Li, J.; Sun, J.; Wang, Y.; Liang, Z.; Ma, P.; Zhang, D.; Wang, J.; Niu, J. Synthesis, structure, and luminescent properties of a family of lanthanide-functionalized peroxoniobiophosphates. Sci. Rep. 2017, 7, 10653. [CrossRef]

7. Liu, Z.; Zhang, Z.F.; Tam, H.-Y.; Tao, X. Multifunctional Smart Optical Fibers: Materials, Fabrication, and Sensing Applications. Photonics 2019, 6, 48. [CrossRef]

8. Zmojda, J.; Miluski, P.; Kochanowicz, M. Nanocomposite Antimony-Germanate-Borate Glass Fibers Doped with $\mathrm{Eu}^{3+}$ Ions with Self-Assembling Silver Nanoparticles for Photonic Applications. Appl. Sci. 2018, 8, 790. [CrossRef]

9. Som, T.; Karmakar, B. Optical properties of $\mathrm{Eu}^{3+}$-doped antimony-oxide-based low phonon disordered matrices. J. Phys. Condens. Matter 2009, 22, 035603. [CrossRef]

10. Rolli, R.; Camagni, P.; Samoggia, G.; Speghini, A.; Wachtler, M.; Bettinelli, M. Fluorescence line narrowing spectroscopy of a lead germanate glass doped with $\mathrm{Eu}^{3+}$. Spectrochim. Acta Part A Mol. Biomol. Spectrosc. 1998, 54, 2157-2162. [CrossRef]

11. Żur, L. Structural and luminescence properties of $\mathrm{Eu}^{3+}, \mathrm{Dy}^{3+}$ and $\mathrm{Tb}^{3+}$ ions in lead germanate glasses obtained by conventional high-temperature melt-quenching technique. J. Mol. Struct. 2013, 1041, 50-54. [CrossRef]

12. Sołtys, M.; Pisarska, J.; Leśniak, M.; Sitarz, M.; Pisarski, W.A. Structural and spectroscopic properties of lead phosphate glasses doubly doped with $\mathrm{Tb}^{3+}$ and $\mathrm{Eu}^{3+}$ ions. J. Mol. Struct. 2018, 1163, 418-427. [CrossRef]

13. Pisarski, W.A.; Żur, L.; Pisarska, J. Optical transitions of $\mathrm{Eu}^{3+}$ and $\mathrm{Dy}^{3+}$ ions in lead phosphate glasses. Opt. Lett. 2011, 36, 990-992. [CrossRef] [PubMed]

14. Ragin, T.; Baranowska, A.; Kochanowicz, M.; Zmojda, J.; Miluski, P.; Dorosz, D. Study of Mid-Infrared Emission and Structural Properties of Heavy Metal Oxide Glass and Optical Fibre Co-Doped with $\mathrm{Ho}^{3+} / \mathrm{Yb}^{3+}$ Ions. Materials 2019, 12, 1238. [CrossRef]

15. Prakash, M.R.; Neelima, G.; Kummara, V.K.; Ravi, N.; Viswanath, C.S.D.; Rao, T.S.; Jilani, S.M. Holmium doped bismuth-germanate glasses for green lighting applications: A spectroscopic study. Opt. Mater. 2019, 94, 436-443. [CrossRef]

16. Nalin, M.; Messaddeq, Y.; Ribeiro, S.J.L.; Poulain, M.; Briois, V.; Brunklaus, G.; Rosenhahn, C.; Mosel, B.D.; Eckert, H. Structural organization and thermal properties of the Sb2O3-SbPO4 glass system. J. Mater. Chem. 2004, 14, 3398-3405. [CrossRef]

17. Moustafa, S.Y.; Sahar, M.R.; Ghoshal, S.K. Spectroscopic attributes of Er3+ ions in antimony phosphate glass incorporated with Ag nanoparticles: Judd-Ofelt analysis. J. Alloy. Compd. 2017, 712, 781-794. [CrossRef]

18. Zhang, Q.Y.; Li, T.; Jiang, Z.H.; Ji, X.H.; Buddhudu, S. 980nm laser-diode-excited intense blue upconversion in $\mathrm{Tm}^{3+} / \mathrm{Yb}^{3+}$-codoped gallate-bismuth-lead glasses. Appl. Phys. Lett. 2005, 87, 171911. [CrossRef] 
19. Wen, X.; Tang, G.; Wang, J.; Chen, X.; Qian, Q.; Yang, Z. Tm ${ }^{3+}$ doped barium gallo-germanate glass single-mode fibers for $2.0 \mu \mathrm{m}$ laser. Opt. Express 2015, 23, 7722-7731. [CrossRef]

20. Kochanowicz, M.; Żmojda, J.; Miluski, P.; Baranowska, A.; Ragin, T.; Dorosz, J.; Kuwik, M.; Pisarski, W.A.; Pisarska, J.; Leśniak, M.; et al. $2 \mu \mathrm{m}$ emission in gallo-germanate glasses and glass fibers co-doped with $\mathrm{Yb}^{3+} / \mathrm{Ho}^{3+}$ and $\mathrm{Yb}^{3+} / \mathrm{Tm}^{3+} / \mathrm{Ho}^{3+}$. J. Lumin. 2019, 211, 341-346. [CrossRef]

21. Jewell, J.; Busse, L.; Crahan, K.; Harbison, B.; Aggarwal, I. Optical Properties of BaO-Ga2O3-GeO2 Glasses for Fiber and Bulk Optical Applications; SPIE: Bellingham, WA, USA, 1994; Volume 2287.

22. Jewell, J.M.; Higby, P.L.; Aggarwal, I.D. Properties of BaO-R2O3- Ga2O3-GeO2 (R = Y, Al, La, and Gd) Glasses. J. Am. Ceram. Soc. 1994, 77, 697-700. [CrossRef]

23. Zur, L.; Janek, J.; Pietrasik, E.; Sołtys, M.; Pisarska, J.; Pisarski, W.A. Influence of MO/MF2 modifiers (M = Ca, $\mathrm{Sr}, \mathrm{Ba})$ on spectroscopic properties of $\mathrm{Eu}^{3+}$ ions in germanate and borate glasses. Opt. Mater. 2016, 61, 59-63. [CrossRef]

24. Jadach, R.; Zmojda, J.; Kochanowicz, M.; Miluski, P.; Lesniak, M.; Sołtys, M.; Pisarska, J.; Pisarski, W.; Lukowiak, A.; Sitarz, M.; et al. Spectroscopic Properties of Rare Earth Doped Germanate Glasses; SPIE: Bellingham, WA, USA, 2018; Volume 10683.

25. Szal, R.; Zmojda, J.; Kochanowicz, M.; Miluski, P.; Dorosz, J.; Lesniak, M.; Jeleń, P.; Starzyk, B.; Sitarz, M.; Kuwik, M.; et al. Spectroscopic properties of antimony modified germanate glass doped with $\mathrm{Eu}^{3+}$ ions. Ceram. Int. 2019, 45, 24811-24817. [CrossRef]

26. Nassar, E.; Ciuffi, K.; Calefi, P.; Ávila, L.; Bandeira, L.; Cestari, A.; Marçal, A.L.; Matos, M. Europium III: Different Emission Apectra in Different Matrices, the Same Element; Nova Science Publishers: Hauppauge, NY, USA, 2010.

27. Jha, K.; Jayasimhadri, M. Structural and emission properties of $\mathrm{Eu}^{3+}$-doped alkaline earth zinc-phosphate glasses for white LED applications. J. Am. Ceram. Soc. 2017, 100, 1402-1411. [CrossRef]

28. Baranowska, A.; Leśniak, M.; Kochanowicz, M.; Żmojda, J.; Miluski, P.; Dorosz, D. Crystallization Kinetics and Structural Properties of the 45S5 Bioactive Glass and Glass-Ceramic Fiber Doped with $\mathrm{Eu}^{3+}$. Materials 2020, 13, 1281. [CrossRef] [PubMed]

29. Ezerskyte, E.; Grigorjevaite, J.; Minderyte, A.; Saitzek, S.; Katelnikovas, A. Temperature-Dependent Luminescence of Red-Emitting Ba2Y5B5O17: $\mathrm{Eu}^{3+}$ Phosphors with Efficiencies Close to Unity for Near-UV LEDs. Materials 2020, 13, 763. [CrossRef]

30. Bouchouicha, H.; Panczer, G.; de Ligny, D.; Guyot, Y.; Ternane, R. Luminescent properties of Eu-doped calcium aluminosilicate glass-ceramics: A potential tunable luminophore. Opt. Mater. 2018, 85, 41-47. [CrossRef]

31. Han, L.; Zhang, Q.; Song, J.; Xiao, Z.; Qiang, Y.; Ye, X.; You, W.; Lu, A. A novel Eu ${ }^{3+}$-doped phosphate glass for reddish orange emission: Preparation, structure and fluorescence properties. J. Lumin. 2020, 221, 117041. [CrossRef]

32. Rakpanich, S.; Wantana, N.; Kaewkhao, J. Development of bismuth borosilicate glass doped with Eu ${ }^{3+}$ for reddish orange emission materials application. Mater. Today Proc. 2017, 4, 6389-6396. [CrossRef]

33. Orozco Hinostroza, I.E.; Desirena, H.; Hernandez, J.; Molina, J.; Moreno, I.; De la Rosa, E. Eu ${ }^{3+}$-doped glass as a color rendering index enhancer in phosphor-in-glass. J. Am. Ceram. Soc. 2018, 101, 2914-2920. [CrossRef]

34. Park, J.Y.; Chung, J.W.; Park, S.J.; Yang, H.K. Versatile fluorescent CaGdAlO4:Eu ${ }^{3+}$ red phosphor for latent fingerprints detection. J. Alloy. Compd. 2020, 824, 153994. [CrossRef]

35. Gui, R.; Jin, H.; Bu, X.; Fu, Y.; Wang, Z.; Liu, Q. Recent advances in dual-emission ratiometric fluorescence probes for chemo/biosensing and bioimaging of biomarkers. Coord. Chem. Rev. 2019, 383, 82-103. [CrossRef]

36. Pilch, M.; Ortyl, J.; Chachaj-Brekiesz, A.; Galek, M.; Popielarz, R. Europium-based luminescent sensors for mapping pressure distribution on surfaces. Sens. Actuators B Chem. 2020, 305, 127409. [CrossRef]

37. Vasilchenko, I.; Carpentiero, A.; Chiappini, A.; Chiasera, A.; Vaccari, A.; Lukowiak, A.; Righini, G.C.; Vereshagin, V.; Ferrari, M. Influence of phosphorous precursors on spectroscopic properties of $\mathrm{Er}^{3+}$-activated SiO2-HfO2-P2O5planar waveguides. J. Phys. Conf. Ser. 2014, 566, 012018. [CrossRef]

38. Pisarska, J.; Kaczmarczyk, B.; Mazurak, Z.; Żelechower, M.; Goryczka, T.; Pisarski, W.A. Influence of P2O5 concentration on structural, thermal and optical behavior of Pr-activated fluoroindate glass. Phys. B Condens. Matter 2007, 388, 331-336. [CrossRef] 
39. Zmojda, J.; Kochanowicz, M.; Miluski, P.; Baranowska, A.; Pisarski, W.A.; Pisarska, J.; Jadach, R.; Sitarz, M.; Dorosz, D. Optical Characterization of Nano- and Microcrystals of EuPO4 Created by One-Step Synthesis of Antimony-Germanate-Silicate Glass Modified by P2O5. Materials 2017, 10, 1059. [CrossRef] [PubMed]

40. Kulshreshtha, S.K.; Jayakumar, O.D.; Vishwanadh, B.; Sudarsan, V. Probing the interface of core shell particles of GaPO4 and AlPO4 by 31P MAS NMR spectroscopy. Solid State Sci. 2011, 13, 484-487. [CrossRef]

41. Labéguerie, P.; Harb, M.; Baraille, I.; Rérat, M. Structural, electronic, elastic, and piezoelectric properties of $\alpha$-quartz and M X O $4(\mathrm{M}=\mathrm{Al}, \mathrm{Ga}, \mathrm{Fe} ; \mathrm{X}=\mathrm{P}, \mathrm{As})$ isomorph compounds: A DFT study. Phys. Rev. B 2010, 81, 045107. [CrossRef]

42. Jadach, R.; Zmojda, J.; Kochanowicz, M.; Miluski, P.; Pisarska, J.; Pisarski, W.A.; Sołtys, M.; Lesniak, M.; Sitarz, M.; Dorosz, D. Investigation of the aluminum oxide content on structural and optical properties of germanium glasses doped with RE ions. Spectrochim. Acta Part A Mol. Biomol. Spectrosc. 2018, 201, 143-152. [CrossRef]

43. Michel, D.; Colomban, P.; Abolhassani, S.; Voyron, F.; Kahn-Harai, A. Germanium mullite: Structure and vibrational spectra of gels, glasses and ceramics. J. Eur. Ceram. Soc. 1996, 16, 161-168. [CrossRef]

44. Kochanowicz, M.; Zmojda, J.; Miluski, P.; Jelen, P.; Sitarz, M.; Dorosz, D. Spectroscopic investigations of $\mathrm{Yb}^{3+} / \mathrm{Ho}^{3+}$ and $\mathrm{Yb}^{3+} / \mathrm{Tm}^{3+} / \mathrm{Ho}^{3+}$ co-doped germanate glasses and optical fibers. In Proceedings of the 2016, 18th International Conference on Transparent Optical Networks (ICTON), Trento, Italy, 10-14 July 2016; pp. 1-4.

45. Zmojda, J.; Kochanowicz, M.; Miluski, P.; Leśniak, M.; Sitarz, M.; Pisarski, W.; Pisarska, J.; Dorosz, D. Effect of $\mathrm{GeO} 2$ content on structural and spectroscopic properties of antimony glasses doped with $\mathrm{Sm}^{3+}$ ions. J. Mol. Struct. 2016, 1126, 207-212. [CrossRef]

46. Zhang, L.Y.; Li, H.; Hu, L.L. Statistical structure analysis of $\mathrm{GeO} 2$ modified $\mathrm{Yb}^{3+}$ : Phosphate glasses based on Raman and FTIR study. J. Alloy. Compd. 2017, 698, 103-113. [CrossRef]

47. Stoch, P.; Stoch, A.; Ciecinska, M.; Krakowiak, I.; Sitarz, M. Structure of phosphate and iron-phosphate glasses by DFT calculations and FTIR/Raman spectroscopy. J. Non-Cryst. Solids 2016, 450, 48-60. [CrossRef]

48. Stefanovsky, S.V.; Stefanovsky, O.I.; Danilov, S.S.; Kadyko, M.I. Phosphate-based glasses and glass ceramics for immobilization of lanthanides and actinides. Ceram. Int. 2019, 45, 9331-9338. [CrossRef]

49. Jha, P.K.; Pandey, O.P.; Singh, K. FTIR spectral analysis and mechanical properties of sodium phosphate glass-ceramics. J. Mol. Struct. 2015, 1083, 278-285. [CrossRef]

50. Higby, P.L.; Aggarwal, I.D. Properties of barium gallium germanate glasses. J. Non-Cryst. Solids 1993, 163, 303-308. [CrossRef]

51. Sadiq, M.; Bensitel, M.; Nohair, K.; Leglise, J.; Lamonier, C. Effect of calcination temperature on the structure of vanadium phosphorus oxide materials and their catalytic activity in the decomposition of 2-propanol. J. Saudi Chem. Soc. 2012, 16, 445-449. [CrossRef]

52. Han, C.; Wang, Z.; Wu, Q.; Yang, W.; Yang, H.; Xue, X. Evaluation of the role of inherent $\mathrm{Ca}^{2+}$ in phosphorus removal from wastewater system. Water Sci. Technol. 2015, 73, 1644-1651. [CrossRef]

53. Binnemans, K. Interpretation of europium (III) spectra. Coord. Chem. Rev. 2015, 295, 1-45. [CrossRef]

54. Kindrat, I.I.; Padlyak, B.V. Luminescence properties and quantum efficiency of the Eu-doped borate glasses. Opt. Mater. 2018, 77, 93-103. [CrossRef]

55. Rice, D.K.; DeShazer, L.G. Spectral Broadening of Europium Ions in Glass. Phys. Rev. 1969, 186, $387-392$. [CrossRef]

56. You, H.; Nogami, M. Optical Properties and Local Structure of Eu ${ }^{3+}$ Ions in Sol-Gel TiO2-SiO2 Glasses. J. Phys. Chem. B 2004, 108, 12003-12008. [CrossRef]

57. Wen, H.; Jia, G.; Duan, C.-K.; Tanner, P.A. Understanding Eu ${ }^{3+}$ emission spectra in glass. Phys. Chem. Chem. Phys. 2010, 12, 9933-9937. [CrossRef] [PubMed]

(C) 2020 by the authors. Licensee MDPI, Basel, Switzerland. This article is an open access article distributed under the terms and conditions of the Creative Commons Attribution (CC BY) license (http://creativecommons.org/licenses/by/4.0/). 